\title{
An Experimental Study on the Low Velocity Impact Behavior of Hybrid Epoxy Composites
}

\author{
MARINA BUNEA, IULIAN GABRIEL BIRSAN, ADRIAN CIRCIUMARU* \\ Dunarea de Jos University of Galati, Department of Applied Sciences, Cross-Border Faculty; Research and Development \\ Center for Thermoset Matrix Composites, 47 Domneasca Str., 800008, Galati, Romania
}

\begin{abstract}
The low velocity impact response of hybrid epoxy composites reinforced with plain weave fabrics, ply orientation at various angles and filled stratified matrix was analyzed in this study. The hybrid epoxy composites were subjected to impact tests at 45J and $90 \mathrm{~J}$ of energy levels with drop weight impact machine. The damaged areas were investigated by visual inspection of impacted and nonimpacted surfaces and by tomographic images. It was found that the replacement of certain carbon inner plies with glass ones and the modification of fiber orientation improved the damage resistance of the hybrid composites with aramid outer layers subjected to impact loading at 45J of energy level.
\end{abstract}

Keywords: polymer-matrix composites; hybrid laminates; impact behavior; delamination

\section{Introduction}

Fiber reinforced thermosetting composites are used increasingly in domains as aeronautics, automotive, naval, military, etc. due to their high stiffness, strength, damage tolerance, lightweight and low cost as compared to the metallic materials. For example, carbon fiber reinforced polymeric composites are often used in aeronautical industry due to their excellent stiffness, mechanical properties and lightweight, which are important for flight performance. Also, the most of sport goods materials used for Formula 1 racing, aquatic goods, winter equipment, etc. are, also, made of carbon composites $[1,2]$. The glass fiber reinforced epoxy composites are used in naval $[3,4]$ and automotive industry fields due to excellent mechanical properties and corrosive resistance. The composites reinforced with aramid fibers are used for defense applications due to their high impact resistance [5,6].

During service life the fiber reinforced polymeric composites can be subjected to low velocity impact loadings due to dropping of the tools during maintenance or due to birds, hail and runways debris during aircraft take-off or landing [7]. Also, the composites structures can be subjected to high velocity impact loadings such as accidents or military applications. Generally, the fiber reinforced laminate composite exhibits higher damage strength in the longitudinal and lateral directions than in the transverse one. The impact resistance of the fiber reinforced stratified polymeric composites depends on their energy absorption capacity, through structural failure by plastic deformations. The typical damage mechanisms leading to failure of material structures are matrix cracking, delamination, fiber breakage and pull-out. A comparison between unidirectional fiber epoxy composite laminates and fabric reinforced epoxy composites, concluded that the delamination occurred in structure of the ones reinforced with unidirectional fibers may propagate in all three inter-laminar, intra-laminar and trans-laminar directions [8] as compared to the ones reinforced with fabrics, whose delamination propagates in inter-laminar direction and through fiber breakage. So, the plain weave fabric reinforced composites exhibit a higher low velocity impact performance than that of composites reinforced with unidirectional fibers due to their fiber interlacing in two reciprocally perpendicular directions [9] leading to a restriction of delamination propagation within a smaller area [10].

The internal structure damage may occur even in case of low velocity impact with a much reduced energy, which usually begins with matrix cracking leading to the adjacent plies separation and delamination occurrence. When the applied loading increases the delamination propagates through thickness of the composite laminate. The fiber fracture and fabric splitting in the warp and weft yarn directions depends on the amount of the impact energy available to break them. The low velocity impact

*email:adrian.circiumaru@ugal.ro 
strength of fiber reinforced polymeric composites depends on many factors, as matrix and fiber properties, their compatibility, fabric weave type, damage strength and quality of fiber-matrix interface, plate thickness [11], shape and diameter of the impactor [12] and initial experimental test parameters (velocity and height). In order to improve the impact performance of the laminate composites as reinforcements can be used different types of fiber/fabric plies (carbon-glass [13-15], carbon-aramid [16], carbon-basalt [17], glass-basalt [18], basalt-aramid [19], etc.) within a single epoxy matrix combining the desired properties of each fiber type and increasing the damage tolerance. Damghani et al. [20] studied the low velocity impact behavior and residual tensile resistance of the pure carbon ply laminate and carbon-glass hybrid laminates. They found that in case of hybrid laminates the glass plies reduced the damage spread through materials thickness and led to larger inter-laminar damage areas between adjacent carbon and glass plies due to their properties. Chan et al. [21] analyzed the behavior of hybrid epoxy composites reinforced with carbon, glass and basalt fibers subjected to low velocity impact with energy of 50J. They found that hybrid composites with carbon plies placed as core presented the highest impact resistance and energy absorption and the composites reinforced with glass and basalt fibers showed almost similar low velocity impact behavior.

Also, for hybrid composite epoxy materials different types of fillers or metallic wires can be used to improve the material responses. In ref. [22] the authors investigated the damage resistance and energy absorptions of the non-hybrid and hybrid epoxy composites reinforced with glass fibers and wire mesh of stainless steel. They concluded that the addition of stainless steel wire mesh into laminate structures as medial ply improved the low velocity impact strength, stiffness and energy absorption capacity. In order to improve the impact performance of the composite materials different types of the fillers into their polymer matrix can be used as clay [23-25], carbon nanotubes [26-29], carbon nanofibers [30], etc. In this case materials impact performance depends on the fillers properties, shape and dimensions, compatibility and the properties and quality of matrix-filler interface. In ref. [31] it was investigated the influence of the nano-clay and graphene inclusions on the performance of the epoxy laminates reinforced with Kevlar fibers subjected to low velocity impact at 32J of energy. The experimental results showed that by increasing of volume ratio of nano-clay from $2 \%$ to $10 \%$ increased, also, the impact resistance of the Kevlar-epoxy composites, but the graphene inclusions did not improved their impact response. Taraghi et al. [32] studied the low velocity impact performance of the epoxy laminates reinforced with Kevlar woven fibers and multi-walled carbon nanotubes. They found that by addition of $0.5 \mathrm{wt} . \%$ of multi-walled carbon nanotubes into epoxy matrix of the Kevlar laminate led to increasing of absorbed energy to $35 \%$ and of penetration limit to $40 \%$ at ambient temperature.

In this paper it is presented the impact response of the hybrid epoxy composites reinforced with different fabric types, ply orientation at various angles $\left(0^{\circ}, \pm 15^{\circ}, \pm 30^{\circ}, \pm 45^{\circ}\right.$ and $\left.90^{\circ}\right)$ and stratified filled matrix, which were subjected to low velocity impact loading with $45 \mathrm{~J}$ and $90 \mathrm{~J}$ energy levels. Actually, these materials were formed in order to obtain multifunctional advanced composite materials with improved thermal, electrical and mechanical properties and impact resistance. Thus, into prepolymer blend between certain layers filler mixtures of carbon black, aramid powder and barium ferrite were added. In these filler mixtures potatoes starch was added the in order to achieve a uniform distribution of fillers and to avoid their sedimentation during polymerization process due to its swelling into liquid. Bria et al. [33] found that the wt. 10\% of potatoes starch did not influence the thermal, electrical and mechanical properties of epoxy composites.

\section{Materials and methods}

\subsection{Materials}

As polymer matrix of the fabric reinforced hybrid laminates with filled stratified matrix and plies orientation at various angles, it was selected the bi-component epoxy system EPIPHEN RE 4020 - DE 4020 (Bostik) with 100:30 ratio of resin and hardener respectively. The epoxy resin of this system is made almost of Bisphenol A (BPA) and the hardener was made almost of modified aliphatic amines. EPIPHEN system exhibits high adherence and compatibility to all types of fibers and to a large area of 
organic and inorganic fillers. This epoxy system was used due to pre-polymer mixture important characteristics for the formation technique of the hybrid laminates and due to its physical and mechanical properties after complete polymerization carried out during 14 days at laboratory temperature of $23^{\circ} \mathrm{C}$.

The plain weave fabrics were used to form hybrid epoxy laminates with ply orientation at various angles, as: A - $173 \mathrm{~g} / \mathrm{m} 2$ density aramid fabric with 2200 weaving fibers of $1210 d$ tex and fabric thickness of $280 \mu \mathrm{m} ; \mathrm{C}-160 \mathrm{~g} / \mathrm{m} 2$ density carbon fabric with $3 \mathrm{~K}$ weaving fibers of 200 tex and fabric thickness of $260 \mu \mathrm{m} ; \mathrm{G}-163 \mathrm{~g} / \mathrm{m} 2$ density glass fabric with EC9 weaving fibers of 68tex and fabric thickness of $180 \mu \mathrm{m} ; \mathrm{M}-270 \mathrm{~g} / \mathrm{m} 2$ density hybrid fabric with three different alternated fiber types (carbon, aramid and glass) and copper wire in the weft yarn direction and an aramid fiber alternated by two carbon fibers in the warp yarn direction and fabric thickness $330 \mu \mathrm{m}$. The first three weave types of the fabrics were selected due to their similar mechanical properties on both fiber directions [34].

In order to obtain stratified epoxy matrix for hybrid laminates it was used as fillers into pre-polymer mixture potatoes starch, carbon black, aramid powder and barium ferrite.

\subsection{Preparation of hybrid composites}

It was formed by wet lay-up technique five hybrid epoxy laminates reinforced with different fabric types, with ply orientation at various angles $\left(0^{\circ}, \pm 15^{\circ}, \pm 30^{\circ}, \pm 45^{\circ}\right.$ and $\left.90^{\circ}\right)$ and with filled stratified matrix, denoted here by H1, H2, H3, H4 and H5. The microscopic images of the cross sections of hybrid laminates are showed in Figure 1, and the plies configuration is presented in Table 1. All hybrid epoxy laminates were made of 17 fabric plies, whose medial ply is a lamina of hybrid fabric [35-37].

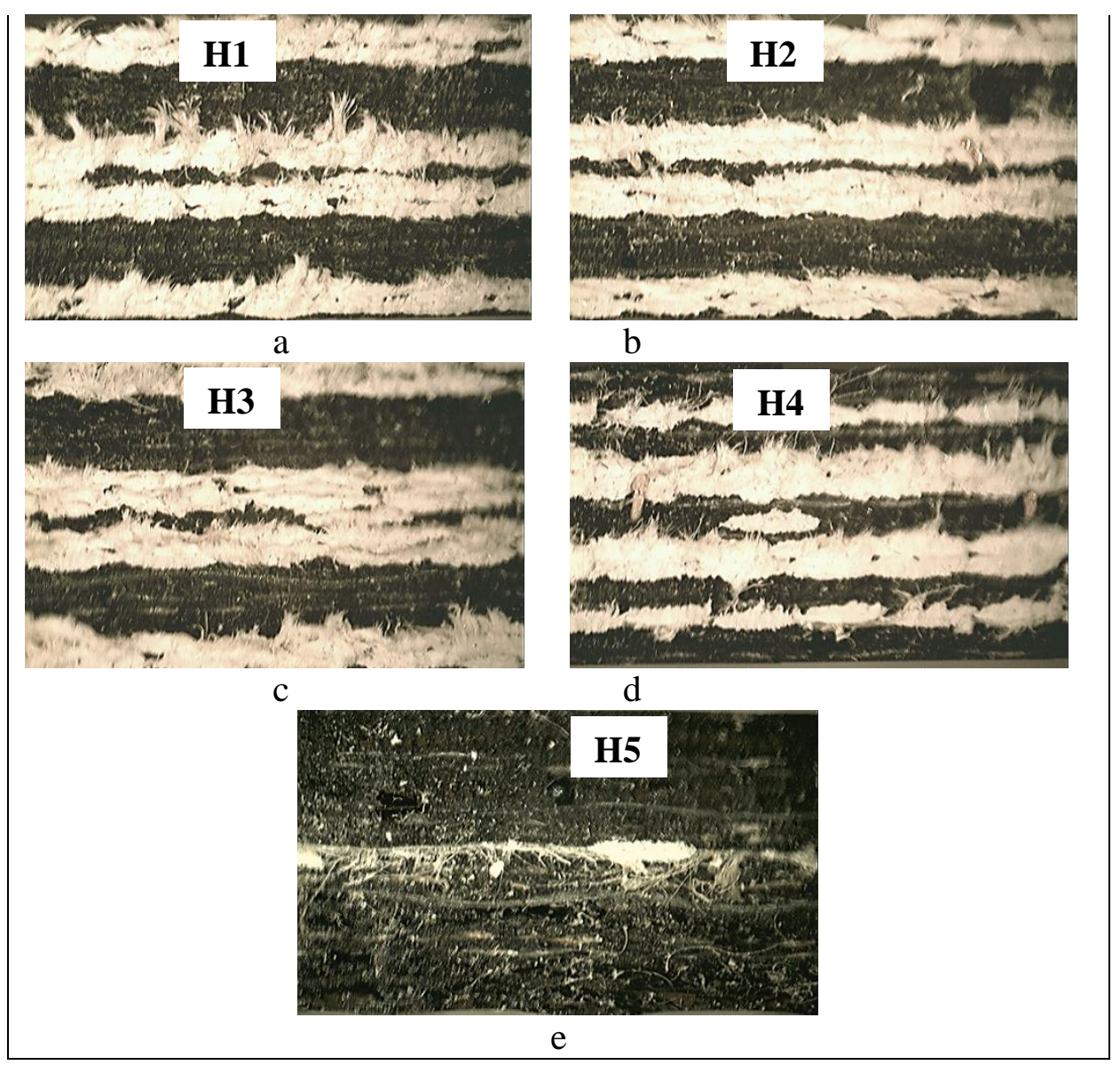

Figure 1. Microscopic images of the cross sections of hybrid epoxy laminates

In order to increase the fiber adherence, which is important for fiber-matrix interface quality, the used plain weave fabrics were treated with three types of solutions as detergent, sodium hydroxide and perchloric acid. To provide fiber stability during the lamina cutting and composite forming wet lay-up 
process, the fabrics were covered with a thin film of epoxy pre-polymer mixed with nitro diluent. Regarding the used fabric types the layers of all laminates presents a symmetrical arrangement relative to the medial ply and an asymmetrical balanced arrangement considering the layer orientation at various angles.

Two filler mixtures were used to modify the epoxy properties by dispersing them into the pre-polymer blend in order to be placed between certain plies, thus obtaining a filled stratified epoxy matrix of hybrid laminates. It can be observed in Table 1, that for outer plies 01 to 05 and 13 to17 it was used the first type of filling mixture EM1 (potatoes starch, carbon black and aramid powder) and for inner plies 06 to 12 it was used the second type of filling mixture EM2 (potatoes starch, carbon black and barium ferrite). In order to provide a uniform distribution of carbon black, aramid powder and barium ferrite into epoxy prepolymer mixtures and to avoid their sedimentation, potatoes starch was used due to its swelling into liquid [33]. All hybrid epoxy laminates were formed at laboratory conditions according to predefined configuration of the plies and were thermally cured after complete polymerization.

Table 1. The architecture of fabric reinforced hybrid composites with filled epoxy matrix

\begin{tabular}{|c|c|c|c|c|c|c|}
\hline \multirow{2}{*}{ 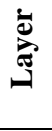 } & \multirow{2}{*}{ Filled stratified matrix } & \multicolumn{5}{|c|}{ Material } \\
\hline & & H1 & $\mathbf{H 2}$ & H3 & H4 & H5 \\
\hline 01 & \multirow{5}{*}{$\begin{array}{c}\text { EM1 } \\
\text { Potatoes starch }+ \text { aramid powder }+ \text { carbon } \\
\text { black } \\
(30 \% \text { total volume ratio })\end{array}$} & A $30^{\circ}$ & A $15^{\circ}$ & A $30^{\circ}$ & $\mathrm{G} 30^{\circ}$ & $\mathrm{C} 45^{\circ}$ \\
\hline 02 & & $\mathrm{~A}-30^{\circ}$ & A $30^{\circ}$ & A $15^{\circ}$ & $\mathrm{C}-30^{\circ}$ & $\mathrm{C}-30^{\circ}$ \\
\hline 03 & & $\mathrm{C} 45^{\circ}$ & $\mathrm{C}-15^{\circ}$ & $\mathrm{C} 0^{\circ}$ & $\mathrm{A} 0^{\circ}$ & $\mathrm{G} 15^{\circ}$ \\
\hline 04 & & $\mathrm{C} 0^{\circ}$ & $\mathrm{C}-30^{\circ}$ & $\mathrm{G} 45^{\circ}$ & $\mathrm{G} 45^{\circ}$ & $\mathrm{G} 30^{\circ}$ \\
\hline 05 & & $\mathrm{C} 45^{\circ}$ & $\mathrm{G} 45^{\circ}$ & $\mathrm{G}-30^{\circ}$ & $\mathrm{C} 30^{\circ}$ & $\mathrm{C}-30^{\circ}$ \\
\hline 06 & \multirow{7}{*}{$\begin{array}{l}\text { EM2 } \\
\text { Potatoes starch + carbon } \\
\text { black + barium ferrite } \\
(30 \% \text { total volume ratio })\end{array}$} & $\mathrm{C} 0^{\circ}$ & $\mathrm{C} 15^{\circ}$ & $\mathrm{C}-15^{\circ}$ & A $15^{\circ}$ & $\mathrm{C}^{\circ}$ \\
\hline 07 & & A $15^{\circ}$ & A $30^{\circ}$ & A $30^{\circ}$ & A $45^{\circ}$ & $\mathrm{G} 30^{\circ}$ \\
\hline 08 & & A $30^{\circ}$ & A $45^{\circ}$ & A $45^{\circ}$ & $\mathrm{G} 30^{\circ}$ & $\mathrm{G} 45^{\circ}$ \\
\hline 09 & & $\mathrm{M} 90^{\circ}$ & $\mathrm{M} 90^{\circ}$ & $\mathrm{M} 90^{\circ}$ & $\mathrm{M} 90^{\circ}$ & $\mathrm{M} 90^{\circ}$ \\
\hline 10 & & $\mathrm{~A}-30^{\circ}$ & A $45^{\circ}$ & A $45^{\circ}$ & $\mathrm{G} 30^{\circ}$ & $\mathrm{G} 45^{\circ}$ \\
\hline 11 & & $\mathrm{~A}-15^{\circ}$ & $\mathrm{A}-30^{\circ}$ & A $-30^{\circ}$ & A $45^{\circ}$ & $\mathrm{G}-30^{\circ}$ \\
\hline 12 & & $\mathrm{C} 0^{\circ}$ & $\mathrm{C}-15^{\circ}$ & $\mathrm{C} 15^{\circ}$ & A $-15^{\circ}$ & $\mathrm{C} 0^{\circ}$ \\
\hline 13 & \multirow{5}{*}{$\begin{array}{c}\text { EM1 } \\
\text { Potatoes starch }+ \text { aramid powder }+ \text { carbon } \\
\text { black } \\
(30 \% \text { total volume ratio })\end{array}$} & $\mathrm{C} 45^{\circ}$ & $\mathrm{G} 45^{\circ}$ & G $30^{\circ}$ & $\mathrm{C}-30^{\circ}$ & C $30^{\circ}$ \\
\hline 14 & & $\mathrm{C} 0^{\circ}$ & C $30^{\circ}$ & $\mathrm{G} 45^{\circ}$ & $\mathrm{G} 45^{\circ}$ & $\mathrm{G}-30^{\circ}$ \\
\hline 15 & & $\mathrm{C} 45^{\circ}$ & C $15^{\circ}$ & $\mathrm{C} 0^{\circ}$ & $\mathrm{A} 0^{\circ}$ & $G-15^{\circ}$ \\
\hline 16 & & A $30^{\circ}$ & $\mathrm{A}-30^{\circ}$ & A $-15^{\circ}$ & C $30^{\circ}$ & C $30^{\circ}$ \\
\hline 17 & & A $-30^{\circ}$ & A $-15^{\circ}$ & A $-30^{\circ}$ & $\mathrm{G}-30^{\circ}$ & $\mathrm{C} 45^{\circ}$ \\
\hline
\end{tabular}

\subsection{Details of thermal measurements}

The experimental tests of low velocity impact were performed using CEAST Fractovis Plus 9350 machine, the drop-weight impact system and data acquisition and evaluation software VisualIMPACT. Based on the variation of impact height and total weight, it was obtained the impact energy level. Constant impact height of $920 \mathrm{~mm}$ was used and variable crosshead weight arrangement of $5.045 \mathrm{~kg}$ and $10.044 \mathrm{~kg}$ for 45.515J and 90.629 J impact energy levels, respectively. The impactor of drop-weight impact system had a hemispherical head with $20 \mathrm{~mm}$ diameter. All low velocity impact tests were carried out at constant impact velocity of $4.248 \mathrm{~m} / \mathrm{s}$, according to EN ISO 6603:2000 standard [38, 39]. As specimens were used plates of $190 \times 190 \mathrm{~mm}$ subjected to impact tests in four points. All low velocity impact tests at $45 \mathrm{~J}$ and 
90J energy levels were performed at laboratory conditions.

\section{Results and discussions}

The key impact parameters as peak load, maximum contact time, peak and permanent deflections, impact and absorbed energies were investigated in order to study the low velocity impact strength of some hybrid epoxy composites reinforced with different fabric types, with ply orientation at various angles $\left(0^{\circ}, \pm 15^{\circ}, \pm 30^{\circ}, 45^{\circ}\right.$ and $\left.90^{\circ}\right)$ and filled stratified matrix. In Figure 2 are plotted the load vs. deflection and load vs. time curves of the hybrid composite materials subjected to low velocity impact at $90 \mathrm{~J}$ of energy, where it can be observed that all composites were perforated by impactor.

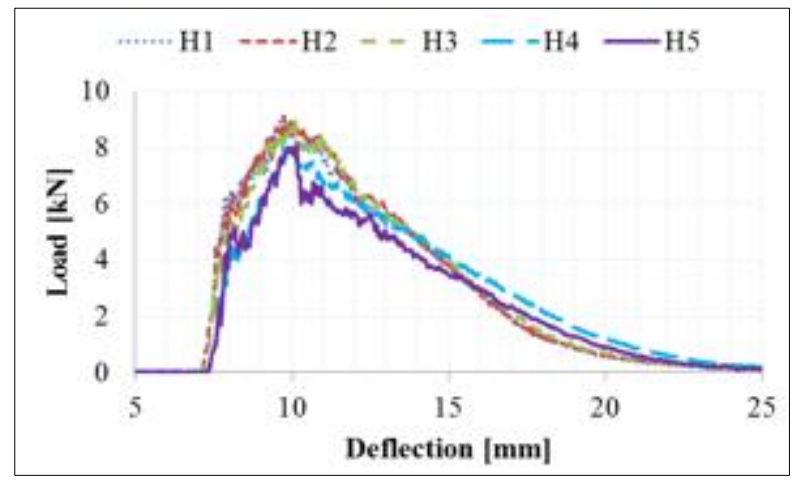

a

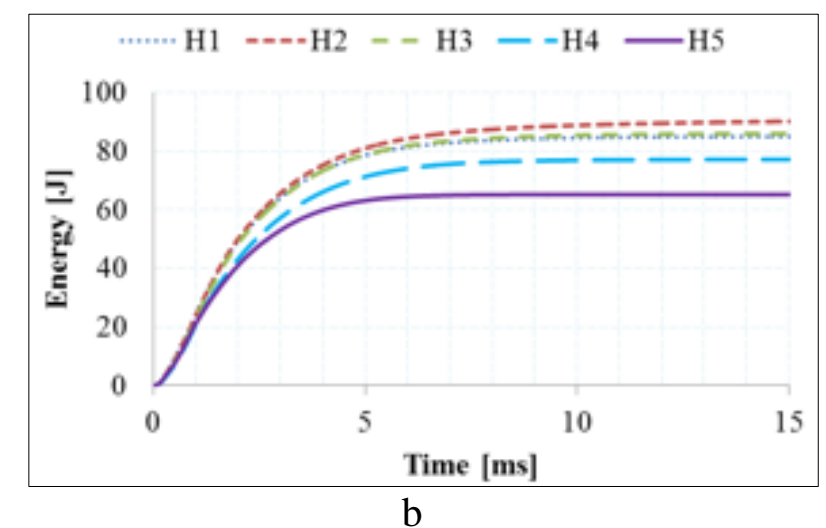

Figure 2. Low velocity impact history curves of the hybrid composite materials at $90 \mathrm{~J}$ of energy: a) load vs. deflection curves and b) load vs. time curves

The behavior of the hybrid composite materials subjected to low velocity impact at $45 \mathrm{~J}$ of energy can be investigated based on load vs. deflection, load vs. time and energy vs. time curves plotted in Figure 3. The load vs. deflection curves (Figure 3a) show the impactor rebounding case from the surface of all hybrid composite plates at the end of each contact time. It can be observed that the hybrid composites with aramid outer plies ( $\mathrm{H} 1, \mathrm{H} 2$ and $\mathrm{H} 3)$ presented a better impact response as compared to the hybrid composites with outer plies made of glass fabric (H4) and carbon fabric (H5). The hybrid composite materials with aramid fibers outer plies showed almost the same impact behavior. In the case of these hybrid composites $\mathrm{H} 1, \mathrm{H} 2$ and $\mathrm{H} 3$ the addition and increasing of the glass ply number into the composite structure by the replacement of certain inner carbon plies with the glass ones led to the improvement of their low velocity impact response. Comparing the hybrid composites with outer aramid fabric plies, it can be seen that the highest peak load $(9.6 \mathrm{kN})$ and lowest permanent deflection $(0.2 \mathrm{~mm})$ were recorded in the case of the hybrid composite material $\mathrm{H} 3$ and the highest peak deflection $(6.4 \mathrm{~mm})$ was exhibited by the hybrid composite material H1 due to its high number of carbon plies.

It can be noticed that the lowest impact resistance was obtained in case of hybrid composite material with outer carbon fibers plies and without inner aramid layers, whose deterioration began in the incipient phase by matrix cracking and delamination occurrence. The incipient phase can be identified on the incipient load section $F_{i}$, which occurred before it was reached the maximum contact load value. The load vs. time curves of the investigated hybrid epoxy laminates (Figure $3 b$ ) shows that the composites with aramid fabric outer plies exhibit higher impact resistance due to higher peak load values as compared to those of the composites with glass or carbon fabric outer plies. It can be noticed that these curves exhibit similar low velocity impact behavior for all hybrid composite plates with aramid fibers outer plies. Also, the load vs. time curves shows the poorest impact response in case of the composites with carbon fibers outer plies and without aramid inner layers (H5), the incipient load section Fi can be identified as the incipient damage. It can be observed that the impact strength of the hybrid composite laminates decreases when the maximum impact contact time increases. So, for hybrid composite plates with aramid fabrics outer plies, it was recorded the similar maximum contact time value (8ms). The 
highest value of maximum impact contact time $(11 \mathrm{~ms})$ was determined in the case of hybrid composite plate with carbon fibers outer layers.

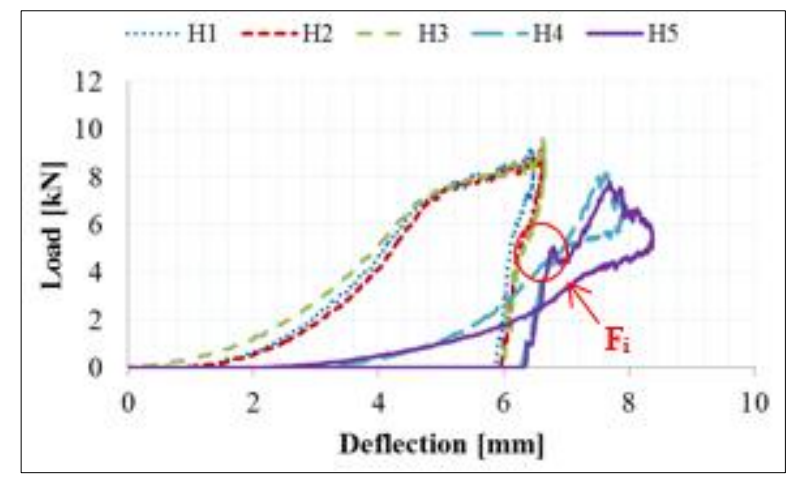

$\mathrm{a}$

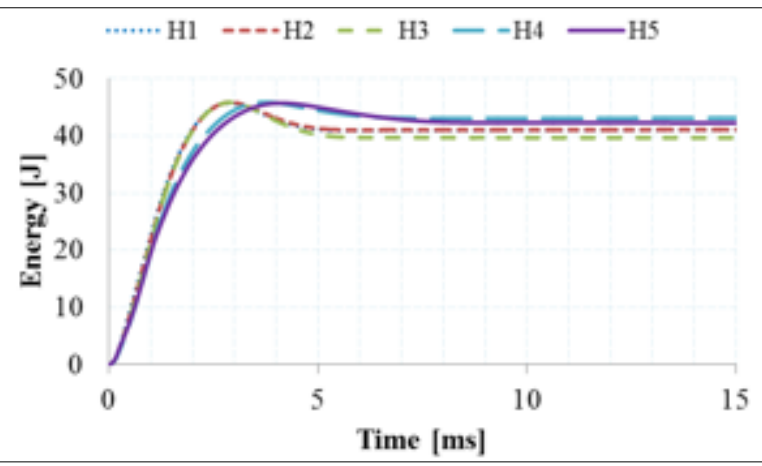

c

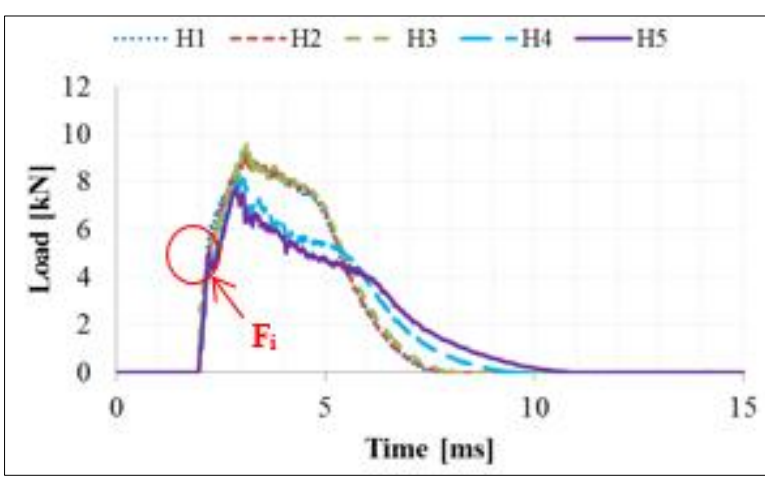

b

Figure 3. Low velocity impact history curves of the hybrid composite materials at 45J of energy:

a) load vs. deflection curves, b) load vs. time curves and c) energy vs. time curves

The energy vs. time of the investigated composite materials are plotted in Figure $3 \mathrm{c}$, and shows a better low velocity impact response in the case of the hybrid composites with aramid outer plies as compared with the ones with carbon and glass outer plies. It can be remarked that the hybrid epoxy composites with aramid outer plies exhibited almost similar impact behavior. It can be seen that the lowest absorbed impact energy was found in case of the epoxy hybrid composite made of aramid outer plies and the most inner glass layers. The absorbed energy is identified on the constant values portion of the energy vs. time curves, which appears after the impact energy achieves the maximum values.

In Figure 4 are presented the obtained data of absorbed energy for epoxy hybrid composites reinforced with different fabric types, fiber orientation at various angles and filled stratified matrix. The values of absorbed energy were determined by difference between those of total energy and energy at maximum load [9]. It can be remarked that the hybrid epoxy laminates with carbon and glass outer plies showed much higher values of absorbed energy as compared to the ones made of aramid outer layers. The highest value of absorbed energy (25J) was exhibited by the hybrid epoxy laminate with carbon outer plies. A comparison between the composite materials with aramid outer layers, it can be observed that the replacement of certain carbon plies with the glass ones and the modification of plies orientation led to the variation of absorbed energy values. The lowest value of absorbed energy (13.7J) was determined in case of the epoxy composite material with aramid outer plies and the most glass inner layers. The hybrid composite material with aramid outer plies and without inner glass layers showed absorbed energy value of 14J. It can be observed that the replacement of the fifth and thirteenth carbon plies with glass ones and the modification of fiber orientation, as in the case of hybrid composite material $\mathrm{H} 2$, led to an increase in absorbed energy (15.8J). 


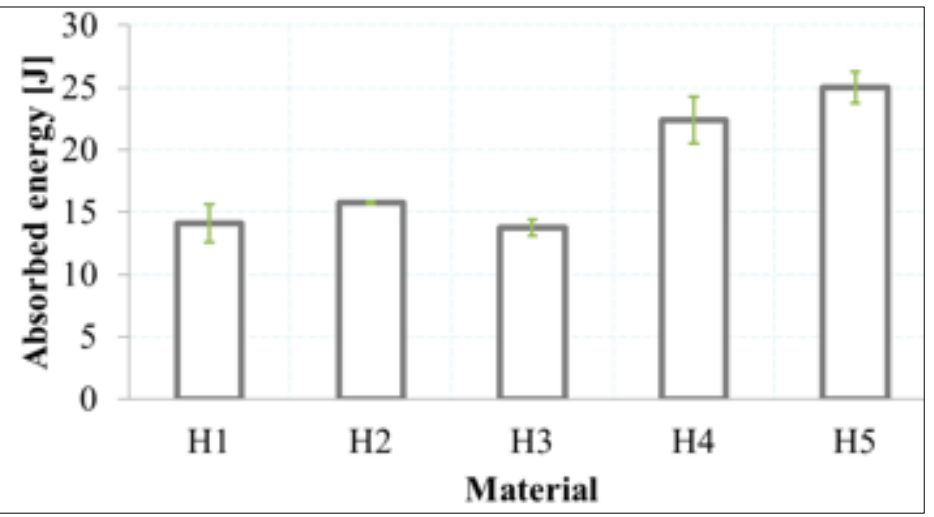

Figure 4. Average absorbed energy of the fabric reinforced hybrid composites with filled epoxy matrix and various fiber orientations

The damaged area of the hybrid epoxy laminates reinforced with different fabric types, fiber orientation at various angles and filled stratified matrix subjected to low velocity impact loading at 45J of energy level are showed in Figure 5, where top (impacted) and bottom (non-impacted) surfaces are presented at the sides and the tomographic images of damaged area at each $5 \mathrm{~mm}$ are presented in the middle.

It can be noticed that the hybrid epoxy composites with higher energy absorption capacity suffered more severe damage due to the fact that the impact energy is absorbed through various mechanisms of failure by the composite materials such as matrix cracking, delamination, fiber breakage and pull out [40]. Generally, the damaged area of all investigated hybrid epoxy composites show multiple interlaminar delamination due to their various fiber orientations, because the propagation direction and shape of the delamination are influenced by fiber directions of two adjacent plies [41,42]. Also, it can be observed that the hybrid epoxy composite materials suffered translaminar delamination, back face splitting in the both fiber directions of the fabrics and fiber pull out.

It can be seen by inspection of the images of top and bottom surfaces and tomographic images that the hybrid composite materials with glass and carbon outer layers subjected to low velocity impact at $45 \mathrm{~J}$ suffered more severe damages in comparison to the ones with aramid outer plies. The hybrid epoxy composite with carbon outer plies (H5) shows multiple delaminations due to fiber orientation at various angles and plies fracture through plate thickness. A larger delamination with an area of almost $126 \mathrm{~mm}^{2}$ can be observed between adjacent glass and carbon lower plies due to their different levels of rigidity. The hybrid epoxy composite with glass outer plies (H4) presents two large delamination zones between middle plies and plies fracture in the translaminar direction. Comparing the hybrid epoxy composite materials with aramid outer plies, it can be observed that the replacement of the certain carbon inner plies with the glass ones led to the improvement of the damage resistance. The first hybrid epoxy composite with aramid fibers outer plies and without inner glass layers (H1) suffered multiple delaminations due to various fiber orientation and different fabric types used as layers. It can be remarked by tomographic images investigation that the plies fracture of this composite begins from upper carbon inner plies and propagates through plate thickness till lower outer ply. The hybrid epoxy composite materials with certain carbon inner plies replaced with glass lamina and with modified fiber orientation ( $\mathrm{H} 2$ and $\mathrm{H} 3$ ) present delaminations between adjacent plies made of aramid and hybrid fabrics and between adjacent plies made of aramid and carbon fabrics. The fracture plies in case of these composite materials begins from middle ply and propagates till lower outer layer. Comparing the hybrid epoxy composite materials with aramid fibers outer layers and glass inner plies ( $\mathrm{H} 2$ and $\mathrm{H} 3$ ) by visual investigation of images of top and bottom surfaces, it can be observed that the one made of fewer inner glass plies (H2) suffered a more severe damage of bottom surface as compared to the one with more inner glass plies (H3). 

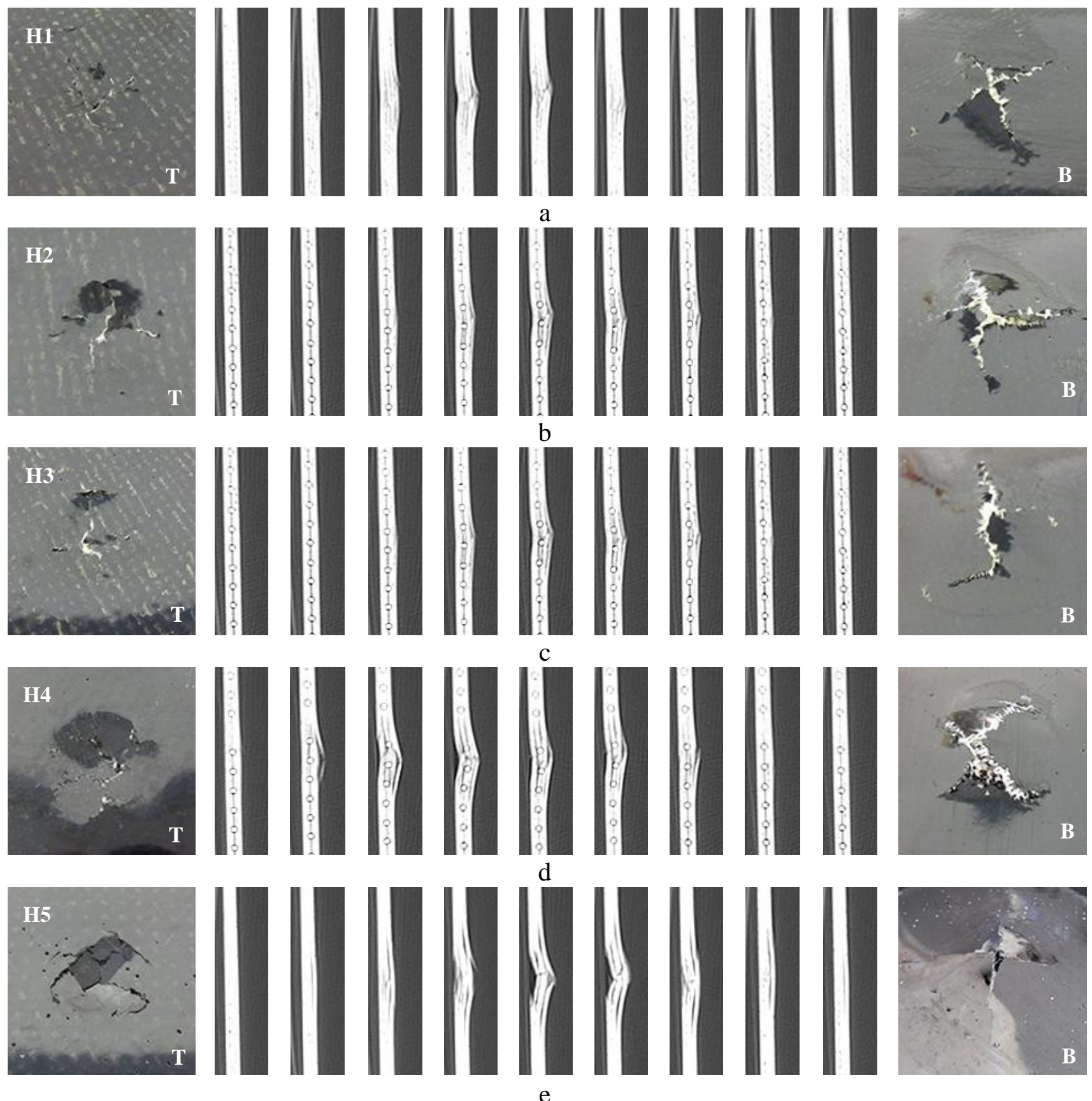

Figure 5. Images of damaged area of the fabric reinforced hybrid composites with filled epoxy matrix and fiber orientation at various angles: a) $\mathrm{H} 1$; b) $\mathrm{H} 2$; c) $\mathrm{H} 3$; d) $\mathrm{H} 4$; e) $\mathrm{H} 5$

\section{Conclusions}

The behavior of hybrid composites reinforced with different types of fabrics, fiber orientation at various angles $\left(0^{\circ}, \pm 15^{\circ}, \pm 30^{\circ}, 45^{\circ}\right.$ and $\left.90^{\circ}\right)$ and filled stratified epoxy matrix subjected to low velocity impact loadings at $45 \mathrm{~J}$ and $90 \mathrm{~J}$ of energy levels was investigated in this research. The following conclusions of this research can be drawn based on the obtained experimental results data plotted in the graphs above and images of damaged areas:

-All hybrid epoxy composite materials subjected to low velocity impact at $90 \mathrm{~J}$ of energy level were perforated by the impactor. In case of low velocity impact tests at $45 \mathrm{~J}$, it was found that the hybrid composites with aramid fibers outer plies showed a better impact response as compared to the ones with outer plies made of glass and carbon fabrics. The low velocity impact strength of hybrid composites with aramid fabric outer plies was improved by replacing of certain inner carbon plies with the glass ones and 
by modifying the ply orientation angles. The lowest impact resistance was exhibited by hybrid composite material with outer carbon fabric plies and without inner aramid layers. It was found that with the increasing of maximum impact contact time, the low velocity impact resistance of the hybrid composite laminates decreases.

-It was recorded that the epoxy hybrid composite with aramid fabrics outer plies and the most inner glass layers exhibited the lowest absorbed impact energy. The replacement of certain inner carbon plies with the glass ones, in case of composite materials with aramid outer plies, led to a variation of the absorbed energy. The epoxy composite material with aramid fibers outer plies and most glass inner layers presented a lower value of absorbed energy as compared to the one without inner glass plies, whose absorbed energy value was $14 \mathrm{~J}$, but by replacing of the fifth and thirteenth carbon plies with the glass ones and modifying of fiber orientation angles it was obtained an increasing of the absorbed energy (15.8J).

-All investigated hybrid epoxy composites showed multiple delamination zones and trans-laminar fractures, back face splitting in the both fiber directions of the fabrics and fiber pull out. Generally, the hybrid epoxy laminates with aramid fibers outer plies presented a lower damage degree as compared to the ones with glass and carbon fabric outer layers. The replacement of the certain carbon inner plies with the glass ones led to the improvement of the damage resistance of the hybrid epoxy composite materials with aramid fabric outer plies.

Acknowledgments: This work has been funded by the European Social Fund through the Sectoral Operational Programme Human Capital 2014-2020, through the Financial Agreement with the title „Burse pentru educaţia antreprenorială în rândul doctoranzilor şi cercetătorilor postdoctorat (Be Antreprenor!)" (in Romanian: "Scholarships for entrepreneurial education among doctoral students and postdoctoral researchers (Be Entrepreneur!)", Contract no. 51680/09.07.2019 - SMIS code: 124539. This work was also supported by the Project "EXPERT", Contract no. 14PFE/17.10.2018.

\section{References}

1.WANG J.L., Application of Composite Materials on Sports Equipments, Applied Mechanics and Materials, 155, 2012, 903-906. https://doi.org/10.4028/www.scientific.net/AMM.155-156.903

2.SUN L.N., DENG Z., The Carbon Fiber Composite Materials Application in Sports Equipment, Advanced Materials Research, 341, 2011, 173-176.

https://doi.org/10.4028/www.scientific.net/AMR.341-342.173

3.GARCIA-ESPINEL J.D., CASTRO-FRESNO D., PARBOLE GAYO P., BALLESTER-MUÑOZ F., Effects of sea water environment on glass fiber reinforced plastic materials used for marine civil engineering constructions, Materials \& Design, 66, 2015, 46-50.

https://doi.org/10.1016/j.matdes.2014.10.032

4.RUBINO F., NISTICÒ A., TUCCI F., CARLONE P., Marine Application of Fiber Reinforced Composites: A Review, Journal of Marine Science and Engineering, 8, 2020, 26.

https://doi.org/10.3390/jmse8010026

5.WANG L., KANESALINGAM S., NAYAK R., PADHYE R., Recent Trends in Ballistic Protection. Textiles and Light, Industrial Science and Technology, 3, 2014, 37.

https://doi.org/10.14355/tlist.2014.03.007

6.ZHU J., TIAN Y.Y., Applications of Advanced Composite Materials in Bullet-Proof Fields and their Study, Advanced Materials Research, 391-392, 2011, 242-245.

https://doi.org/10.4028/www.scientific.net/AMR.391-392.242

7.KHASHABA U.A., OTHMAN R., Low-velocity impact of woven CFRE composites under different temperature levels, International Journal of Impact Engineering, 108, 2017, 191-204. https://doi.org/10.1016/j.ijimpeng.2017.04.023

8.BRUNNER A.J., Fracture mechanics characterization of polymer composites for aerospace applications, Polymer Composites in the Aerospace Industry, Elsevier, 2015, 191-230. 
https://doi.org/10.1016/B978-0-85709-523-7.00008-6

9.HOSUR M.V., ADBULLAH M., JEELANI S., Studies on the low-velocity impact response of woven hybrid composites, Composite Structures, 67, 2005, 253-262.

https://doi.org/10.1016/j.compstruct.2004.07.024

10.EVCI C., GÜLGEÇ M., An experimental investigation on the impact response of composite materials, International Journal of Impact Engineering, 43, 2012, 40-51.

https://doi.org/10.1016/j.ijimpeng.2011.11.009

11.REDDY T.S., MOGULANNA K., REDDY K.G., SUBBA REDDY P.R., MADHU V., Effect of thickness on behaviour of E-glass/epoxy composite laminates under low velocity impact, Procedia Structural Integrity, 14, 2019, 265-272. https://doi.org/10.1016/j.prostr.2019.05.034

12.SEVKAT E., LIAW B., DELALE F., Drop-weight impact response of hybrid composites impacted by impactor of various geometries, Materials \& Design, 52, 2013, 67-77.

https://doi.org/10.1016/j.matdes.2013.05.016

13.ZHANG C., RAO Y., LI W., Low-velocity impact behavior of intralayer hybrid composites based on carbon and glass non-crimp fabric, Composite Structures, 234, 2020, 111713.

https://doi.org/10.1016/j.compstruct.2019.111713

14.ROGANI A., NAVARRO P., MARGUET S., FERRERO J-F, LANOUETTE C., Tensile post-impact behaviour of thin carbon/epoxy and glass/epoxy hybrid woven laminates - Part I: Experimental study, Composite Structures, 230, 2019, 111508.

https://doi.org/10.1016/j.compstruct.2019.111508

15.SWOLFS Y., GEBOES Y., GORBATIKH L., PINHO S.T., The importance of translaminar fracture toughness for the penetration impact behaviour of woven carbon/glass hybrid composites, Composites Part A: Applied Science and Manufacturing, 103, 2017, 1-8.

https://doi.org/10.1016/j.compositesa.2017.09.009

16.WAGIH A., SEBAEY T.A., YUDHANTO A., LUBINEAU G., Post-Impact Flexural Behavior of Carbon-Aramid/Epoxy Hybrid Composites, Composite Structures, 2020, 112022.

https://doi.org/10.1016/j.compstruct.2020.112022

17.TIRILLÒ J., FERRANTE L., SARASINI F., LAMPANI L., BARBERO E., SÁNCHEZ-SÁEZ S., VALENTE T., GAUDENZI P., High velocity impact behaviour of hybrid basalt-carbon/epoxy composites, Composite Structures, 168, 2017, 305-312.

https://doi.org/10.1016/j.compstruct.2017.02.039

18.SARASINI F., TIRILLÒ J., VALENTE M., VALENTE T., CIOFFI S., IANNACE S., SORRENTINO L., Effect of basalt fiber hybridization on the impact behavior under low impact velocity of glass/basalt woven fabric/epoxy resin composites, Composites Part A: Applied Science and Manufacturing, 47, 2013, 109-123. https://doi.org/10.1016/j.compositesa.2012.11.021

19.KHAZAIE M., ESLAMI-FARSANI R., SAEEDI A., Evaluation of repeated high velocity impact on polymer-based composites reinforced with basalt and Kevlar fibers, Materials Today Communications, 17, 2018, 76-81. https://doi.org/10.1016/j.mtcomm.2018.08.016

20.DAMGHANI M., ERSOY N., PIORKOWSKI M., MURPHY A., Experimental evaluation of residual tensile strength of hybrid composite aerospace materials after low velocity impact, Composites Part B: Engineering, 179, 2019, 107537. https://doi.org/10.1016/j.compositesb.2019.107537

21.CHEN D., LUO Q., MENG M., LI Q., SUN G., Low velocity impact behavior of interlayer hybrid composite laminates with carbon/glass/basalt fibres, Composites Part B: Engineering, 176, 2019, 107191. https://doi.org/10.1016/j.compositesb.2019.107191

22.KARUNAGARAN N., BHARATHIRAJA G., MUNIAPPAN A., YOGANANDAM K., Energy absorption and damage behaviour of surface treated glass fibre/stainless steel wire mesh reinforced hybrid composites, Materials Today: Proceedings, 2020. https://doi.org/10.1016/j.matpr.2019.11.305 23.RAFIQ A., MERAH N., BOUKHILI R., AL-QADHI M., Impact resistance of hybrid glass fiber reinforced epoxy/nanoclay composite, Polymer Testing, 57, 2017, 1-11.

https://doi.org/10.1016/j.polymertesting.2016.11.005 
24.MURUGAN P., NARESH K., SHANKAR K., VELMURUGAN R., BALAGANESAN G., High velocity impact damage investigation of carbon/epoxy/clay nanocomposites using 3D Computed Tomography, Materials Today: Proceedings, 5, 2018, 16946-55.

https://doi.org/10.1016/j.matpr.2018.04.098

25.REIS P.N.B., FERREIRA J.A.M., SANTOS P., RICHARDSON M.O.W., SANTOS J.B., Impact response of Kevlar composites with filled epoxy matrix, Composite Structures, 94, 2012, 3520-3528. https://doi.org/10.1016/j.compstruct.2012.05.025

26.XIN W., SARASINI F., TIRILLÒ J., BAVASSO I., SBARDELLA F., LAMPANI L., DE ROSA I.M., Impact and post-impact properties of multiscale carbon fiber composites interleaved with carbon nanotube sheets, Composites Part B: Engineering, 183, 2020, 107711

https://doi.org/10.1016/j.compositesb.2019.107711

27.EL MOUMEN A., TARFAOUI M., LAFDI K., BENYAHIA H., Dynamic properties of carbon nanotubes reinforced carbon fibers/epoxy textile composites under low velocity impact, Composites Part B: Engineering, 125, 2017, 1-8. https://doi.org/10.1016/j.compositesb.2017.05.065

28.KARA M., KIRICI M., TATAR A.C., AVCI A., Impact behavior of carbon fiber/epoxy composite tubes reinforced with multi-walled carbon nanotubes at cryogenic environment, Composites Part B: Engineering, 145, 2018, 145-154. https://doi.org/10.1016/j.compositesb.2018.03.027

29.SOLIMAN E.M., SHEYKA M.P., TAHA M.R., Low-velocity impact of thin woven carbon fabric composites incorporating multi-walled carbon nanotubes, International Journal of Impact Engineering, 47, 2012, 39-47. https://doi.org/10.1016/j.ijimpeng.2012.03.002

30.RAHMAN M.M., HOSUR M., HSIAO K-T., WALLACE L., JEELANI S., Low velocity impact properties of carbon nanofibers integrated carbon fiber/epoxy hybrid composites manufactured by OOA-VBO process, Composite Structures, 120, 2015, 32-40.

https://doi.org/10.1016/j.compstruct.2014.09.053.

31.RAHMAN A.S., MATHUR V., ASMATULU R., Effect of nanoclay and graphene inclusions on the low-velocity impact resistance of Kevlar-epoxy laminated composites, Composite Structures, 187, 2018, 481-488. https://doi.org/10.1016/j.compstruct.2017.12.054

32.TARAGHI I., FEREIDOON A., TAHERI-BEHROOZ F., Low-velocity impact response of woven Kevlar/epoxy laminated composites reinforced with multi-walled carbon nanotubes at ambient and low temperatures, Materials \& Design, 53, 2014, 152-158. https://doi.org/10.1016/j.matdes.2013.06.051.

33.BRIA V., CÎRCIUMARU A., BÎRSAN I.G., Some Properties of Starch/Epoxy Composites, Mater. Plast., 48, 2011, 189-194.

34.CAPATINA A., BRIA V., BUNEA M., BIRSAN I.G., Tensile Behaviour of Fabric Reinforced Laminates and Plies, Mater. Plast., 56, 2019, 370-377. https://doi.org/10.37358/MP.19.2.5188

35.BUNEA M., BOSOANCA R., ENI C., CRISTACHE N., STEFANESCU V., The impact characteristics of fabric reinforced hybrid composites, Materiale Plastice, 54, 2017, 286-290. https://doi.org/10.37358/MP.17.2.4834

36.BUNEA M., CÎRCIUMARU A., BUCIUMEANU M., BÎRSAN I.G., SILVA F.S., Low velocity impact response of fabric reinforced hybrid composites with stratified filled epoxy matrix, Composites Science and Technology, 169, 2019, 242-248. https://doi.org/10.1016/j.compscitech.2018.11.024

37.STEFANESCU V., BUNEA M., CIRCIUMARU A., Impact Analysis of Fabric Reinforced Plates, Materiale Plastice, 52, 2015, 198-203.

38.European Standard EN ISO 6603-1:2000. Determination of puncture impact behaviour of rigid plastics. Part 1: Non-instrumented impact testing, 2000.

39.***European Standard EN ISO 6603-2:2000. Determination of puncture impact behaviour of rigid plastics. Part 2: Instrumented impact testing, 2000.

40.DAVID-WEST O.S., ALEXANDER N.V., NASH D.H., BANKS W.M., Energy absorption and bending stiffness in CFRP laminates: The effect of $45^{\circ}$ plies, Thin-Walled Structures, 46, 2008, 860869. https://doi.org/10.1016/j.tws.2008.01.024 
41.LONG S., YAO X., ZHANG X., Delamination prediction in composite laminates under low-velocity impact, Composite Structures, 132, 2015, 290-298. https://doi.org/10.1016/j.compstruct.2015.05.037. 42.HAZZARD M.K., HALLETT S., CURTIS P.T., IANNUCCI L., TRASK R.S., Effect of fibre orientation on the low velocity impact response of thin Dyneema ${ }^{\circledR}$ composite laminates, International Journal of Impact Engineering, 100, 2017, 35-45. https://doi.org/10.1016/j.ijimpeng.2016.10.007

$\overline{\text { Manuscript received: } 12.05 .2020}$ 